\title{
BIODIVERSITAS KERANG OYSTER (MOLLUSCA, BIVALVIA) DI DAERAH INTERTIDAL HALMAHERA BARAT, MALUKU UTARA
}

\author{
Biodiversity of Oyster (Mollusca, Bivalvia) in the Intertidal \\ of West Halmahera, North Maluku
}

Pieter F Silulu ${ }^{2}$, Farnis B Boneka ${ }^{3}$, Gustaf F. Mamangkey ${ }^{3}$

\begin{abstract}
Biodiversity in coastal areas, whether in the form of genetic, species or ecosystem diversity is a valuable asset for supporting development in Indonesia. This study aimed to figure out the types of oyster, species abundance, diversity and dominant species in the intertidal area of the West coast of Halmahera. Aktivitiy studies conducted in March - Jun 2012 at three sites using belt transects method. The analysis showed abundant species Isognomon isognomon is with density between 0.080 to $0.283 \mathrm{ind} / \mathrm{m}^{2}$, diversity in the category are marked with an index value in the range of 1.109 to 1.644 . Six families of oyster constans were found 8 species, namely Isognomon isognomon, Saccostrea cucullata, Saccostrea sp, Chama limbula, Hyotissa hyotis, Malleus malleus, Spondylus versicolor, Pinctada margaritifera.
\end{abstract}

Keywords : biodiversity, oyster, intertidal, West Halmahera

\section{ABSTRAK}

Keanekaragaman hayati di wilayah pesisir, baik dalam bentuk keanekaragaman genetik, spesies maupun ekosistem merupakan aset yang sangat berharga untuk menunjang pembangunan di Indonesia. Penelitian ini bertujuan untuk mengkaji jenis-jenis oyster, kelimpahan spesies, keanekaragaman dan dominan spesies di daerah intertidal pantai Halmahera Barat. Kegiatan penelitian dilakukan pada bulan Maret - Juni 2012 di tiga stasiun penelitian dengan menggunakan metode transek pita. Hasil analisis menujukkan spesies Isognomon isognomon paling melimpah dengan kepadatan antara 0,080 $-0,283 \mathrm{ind} / \mathrm{m}^{2}$, keanekaragaman dalam kategori sedang ditandai dengan nilai indeks pada kisaran 1,109-1,644. Jenis oyster yang ditemukan 8 jenis yang tergolong dalam 6 famili, yakni Isognomon isognomon, Saccostrea cucullata, Saccostrea sp, Chama limbula, Hyotissa hyotis, Malleus malleus, Spondylus versicolor, Pinctada margaritifera

Kata kunci : keanekaragaman, oyster, intertidal, Halamahera Barat

1 Bagian dari skripsi

2 Mahasiswa Program Studi IImu Kelautan FPIK-UNSRAT

${ }^{3}$ Staf pengajar Fakultas Perikanan dan IImu Kelautan Universitas Sam Ratulangi

\section{PENDAHULUAN}

Wilayah pesisir dan lautan Indonesia memiliki keanekaragaman hayati tertinggi di dunia (mega biodiversity) yang merupakan aset berharga untuk menunjang pembangunan di Indonesia. Daerah intertidal 
adalah wilayah pesisir dengan variasi faktor lingkungan yang terbesar dengan jenis habitat utama yaitu pantai berpasir, berlumpur dan berbatu.

Di daerah ini hidup berbagai jenis organisme aquatik termasuk oyster (bivalvia, Mollusca). Kerang oyster memiliki cangkang kasar dan tidak beraturan. Oyster yang melekatkan diri pada benda-benda keras cenderung mengikuti bentuk permukaan bendabenda tersebut (Dharma, 1988).

Keanekaragaman jenis dan kelimpahan oyster di pantai Barat Halmahera belum didokumentasikan dengan baik. Padahal sebagian dari oyster di wilayah ini dikumpulkan dan dikonsumsi oleh masyarakat lokal. Penelitian ini bertujuan untuk menginventarisasi kekayaan jenis oyster di pantai Halmahera Barat, dengan lokasi yaitu Pulau Gomorotu, Desa Guaria dan Desa Guamaadu. Parameter yang dianalisis mencakup kelimpahan, indeks keanekaragaman spesies, dan indeks dominan spesies.

\section{METODE}

Penelitian ini dilaksanakan di perairan pantai Halmahera Barat. Kabupaten Halmahera Barat salah satu kabupaten di Provinsi Maluku Utara, yang disahkan pada tanggal 25 Februari 2003 berdasarkan Undangundang Nomor 1 Tahun 2003. Sampel diambil pada 3 stasiun penelitian, stasiun 1 Pulau Gomorotu, stasiun 2 Desa Guaeria dan stasiun 3 Desa Guamaadu (Gambar 1).

Pelaksanaan penelitian berlangsung selama 4 bulan yakni antara bulan Maret sampai bulan Juni tahun 2012. Pengumpulan sampel pada bulan Maret dengan metode transek pita (Belt Transect). Pada setiap stasiun penelitian dilakukan 3 kali penarikan transek (belt) secara horizontal sejajar garis pantai dengan berukuran $2 \times 50 \mathrm{~m}^{2}$ (Gambar 2).

Oyster yang berada dalam transek difoto dan diambil, kemudian dimasukan ke dalam kantong plastik yang sudah diberi label. Spesimen diberi pengawet alkohol $70 \%$, di bawah ke laboratorium Biologi Kelautan FPIK UNSRAT. Selanjutnya diidentifikasi, dianalisis, dan penyusunan draft.

Identifikasi menggunakan buku petunjuk antara lain Dharma (1988, 2005), Abbott (1991) dan Dance (1992). Sampel oyster diukur panja ng dan lebar cangkang. Untuk pengukuran panjang cangkang dimulai dari bagian anterior sampai bagian akhir pertumbuhan cangkang, sedangkan pengukuran lebar cangkang dimulai dari batas dorsal sampai batas ventral (Gambar 3).

Analisa data mengikuti beberapa formula berikut ini :

$>$ Ukuran rata-rata panjang dan lebar cangkang serta standar deviasi (Fowler et al. 1998).

$$
\bar{X}=\frac{\sum x i}{n}
$$

dimana :

$\bar{X} \quad=$ Rata-rata

$\sum x \boldsymbol{i}=$ Jumlah individu-individu dalam setiap spesies

$n \quad=$ Jumlah dalam setiap spesies

$$
S D=\sqrt{\frac{\sum x i^{2}\left(\sum x i\right)^{2} l n}{n-1}}
$$

dimana :

$\boldsymbol{S D}=$ Standar deviasi

$\boldsymbol{x} \boldsymbol{i}=$ Ukuran individu ke-i dalam setiap spesies

$\boldsymbol{n}$ = Jumlah spesimen dalam setiap spesies

Kelimpah spesies Kepadatan spesies (Krebs, 1985)

dimana :

$$
D=\frac{N i}{A}
$$

$\boldsymbol{D}=$ Kepadatan spesies

$\mathrm{Ni}=$ Jumlah individu dalam spesies $\mathrm{i}$

$\boldsymbol{A}=$ Luas daerah sampling $\left(\mathrm{m}^{2}\right)$ 
Kepadatan relatif spesies (Krebs, 1985).

dimana :

$$
K R(\%)=\frac{N i}{n} \times 100
$$

$K R=$ Kepadatan relatif spesies

$\mathrm{Ni}=$ Jumlah individu dalam spesies $\mathrm{i}$

$n$ = Jumlah total seluruh spesies

$>$ Indeks keanekaragaman spesies dianalisis dengan menggunakan formula Shannon-Wiener dalam Krebs (1985)

Di mana :

$$
H^{\prime}=-\sum(n i / N \ln n i / N)
$$

$H^{\prime}$ : Indeks keanekaragaman spesies

$n i$ : Jumlah individu spesies ke-i

$N$ : Jumlah total individu.

Keterangan :

$H^{\prime}<1$ : Keanekaragaman rendah dan keadaan komunitas rendah

$1<H^{\prime}<3$ : Keanekaragaman sedang dan keadaan sedang

$\mathrm{H}^{\prime}>3$ : Keanekaragaman tinggi dan keadaan tinggi.

$>$ Indek dominan spesies (Krebs, 1985).

Di mana :

$$
C=\sum(n i / N)^{2}
$$

C : Indeks dominan

$\boldsymbol{n i}$ : Jumlah individu setiap spesies i

$N$ : Jumlah total individu seluruh spesies

Keterangan :
$\mathrm{C}<0,50$
Dominasi rendah
$0,50<\mathrm{C}<0,75$ : Dominasi sedang
$0,75<\mathrm{C}<1$ : Dominasi tinggi

\section{HASIL DAN PEMBAHASAN}

\section{Jenis-jenis Oyster.}

Dari hasil penelitian yang dilakukan pada tiga stasiun penelitian di daerah intertidal pantai barat Halmahera, ditemukan 8 jenis oyster dari 6 famili. Spesies-spesies yang dimaksud terdiri atas: Saccostrea cucullata, Hyotissa hyotis, Saccostrea sp, Chama limbul, Isognomon isognomon, Spondylus versicolor, Malleus malleus, dan Pinctada margaritifera. Selanjutnya secara terpisah spesies pada tiap stasiun dapat dilihat pada Tabel 1.

Dari jenis-jenis yang didapat, ada empat jenis yang umum ditemukan di tiga stasiun yakni Saccostrea cucullata, Isognomon isognomon, Spondylus versicolor dan Pinctada margaritifera. Kemudian ada jenis-jenis yang ditemukan tidak di semua stasiun penelitian seperti Saccostrea sp, Malleus malleus dan Hyotissa hyotis yang ditemukan hanya di dua stasiun. Selanjutnya ada jenis yang hanya ditemukan pada satu stasiun (Pulau Gomorotu) yakni Chama limbula.

Di Indonesia ada sekitar 45 jenis oyster (Dharma, 2005) dengan demikian hanya sebagian kecil oyster terdapat di wilayah Halmahera Barat. Ada berbagai faktor yang mempengaruhi kehadiran jenis-jenis organisme yang kemungkinan juga dapat mempengaruhi penyebaran jenis oyster. Faktor-faktor yang dimaksud adalah faktor lingkungan seperti topografi, jenis substrat, makanan, kedalaman, arus dan gelombang serta interaksi biologis seperti predator (Nybakken, 1992).

\section{Ukuran Cangkang.}

Jenis yang memiliki ukuran yang paling panjang adalah Malleus malleus dengan $\overline{\boldsymbol{X}}=11,36 \mathrm{~cm}$, diikuti oleh Saccostrea sp $\overline{\boldsymbol{X}}=9,23 \mathrm{~cm}$, Hytissa hyotis $8,32 \mathrm{~cm}$, Isognomon isognomon $8,04 \mathrm{~cm}$, Saccostrea cucullata $7,96 \mathrm{~cm}$, Pinctada margaritifera $7,61 \mathrm{~cm}$ dan yang memiliki ukuran yang paling kecil adalah Chama limbula dengan ukuran $\bar{X}=4,48 \mathrm{~cm}$ (Tabel 2).

Samping adanya variasi pada ukuran panjang cangkang, juga bervariasi dalam hal bentuk. Hal ini yang menyebabkan adanya variasi ukuran panjang cangkang. Selain itu, pertumbuhan cangkang juga dipengaruhi oleh ketersediaan kadar kalsium dalam air dan genetik.

\section{Kepadatan}

Hasil analisis kepadatan spesies dan kepadatan relatif spesies oyster di 
daerah intertidal pantai barat Halmahera pada ke 3 stasiun penelitian ditampilkan pada Tabel 3.

Nilai kepadatan spesies oyster tertinggi di Pulau Gomorotu dengan (K) 0,677 ind $/ \mathrm{m}^{2}$, diikuti Desa Guamaadu dengan (K) $0,140 \mathrm{ind} / \mathrm{m}^{2}$ dan Desa Guaeria dengan (K) $0,133 \mathrm{idn} / \mathrm{m}^{2}$. Tingginya kepadatan spesies di Pulau Gomorotu karena didukung oleh variasi ekosistem, misalnya adanya mangrove, padang lamun dan terumbu karang. Ketiga ekosistem ini merupakan penyuplai bahan makanan bagi biota laut termasuk di dalamnya oyster (Dahuri, 2003).

Pada Pulau Gomorotu Isognomon isognomon memiliki nilai kepadatan spesies tertinggi $(K)=0,283 \mathrm{ind} / \mathrm{m}^{2}$ dengan nilai $(K R)=41,87 \%$ untuk spesies, selanjutnya Chama limbula dengan (K) $0,167 \mathrm{ind} / \mathrm{m}^{2}$, Spondylus versicolor dengan $(K) 0,070 \mathrm{ind} / \mathrm{m}^{2}$ dan (KR) 10,34\%, Saccostrea sp dengan (K) $0,043 \mathrm{ind} / \mathrm{m}^{2}$ dan (KR) $6,40 \%$, Malleus malleus dan Hyotissa hyotis masing-masing $(\mathrm{K}) \quad 0,037$ ind $/ \mathrm{m}^{2}$ dengan (KR) $5,41 \%$. Spesies oyster yang memiliki nilai kepadatan spesies (K) terendah untuk stasiun 1 yaitu $0,020 \mathrm{ind} / \mathrm{m}^{2}$ dengan nilai (KR) 2,95\% untuk spesies Saccostrea cucullata dan Pinctada margaritifera.

Di Guamaadu memiliki kepadatan Isognomon isognomon tertinggi yakni $(\mathrm{K})=0,083 \mathrm{ind} / \mathrm{m}^{2}$ dan $(\mathrm{KR})=62,50 \%$, Spondylus versicolor dengan (K) 0,027 ind $/ m^{2}$ dan (KR) $20,00 \%$, Saccostrea sp dengan (K) $0,010 \mathrm{ind} / \mathrm{m}^{2}$ dan (KR) $7,50 \%$. Sedangkan spesies dengan nilai kepadatan terendah dengan $(\mathrm{K})$ $0,007 \mathrm{ind} / \mathrm{m}^{2}$ serta (KR) $5,00 \%$ adalah Saccostrea cucullata dan Pinctada margaritifera.

Pada Guaeria masih ditemukan spesies Isognomon isognomon dengan nilai kepadatan tertinggi $\mathrm{K}=0,080$ ind $/ \mathrm{m}^{2}$ dan $\mathrm{KR}=57,14 \%$ kemudian diikuti oleh Spondylus versicolor $\mathrm{K}=$ $0,023 \mathrm{ind} / \mathrm{m}^{2}$ dan $\mathrm{KR}=16,66 \%$, Saccostera cucullata, Picntada margaritifera dengan $\mathrm{K}=0,013 \mathrm{ind} / \mathrm{m}^{2}$ dan $\mathrm{KR}=9,52 \%$, Hyotissa hyotis dengan $\mathrm{K}=0,006$ ind $/ \mathrm{m}^{2}$ dan $\mathrm{KR}=$ $4,76 \%$. Malleus malleus memiliki kepadatan spesies yang terendah dengan $\mathrm{K}=0,003 \mathrm{ind} / \mathrm{m}^{2}$ dan $\mathrm{KR}=$ 2,38\% (Tabel 3).

Untuk mengenal suatu populasi maka kepadatan biasanya merupakan parameter yang perlu mendapat perhatian. Informasi tentang kepadatan spesies dapat menjadi acuan bagi pengembangan dan pengelolaan jenis oyster bagi masyarakat lokal khususnya dalam bidang budidaya.

\section{Indeks Keanekaragaman dan Indeks Dominan Spesies.}

Hasil analisis yang diperoleh bahwa indeks keanekaragaman spesies bervariasi menurut stasiun penelitian, dimana Pulau Gomorotu memiliki nilai indeks keanekaragaman yang tinggi dengan ' $H^{\prime}=1,6444$, kemudian Desa Guamaadu dengan $\mathrm{H}^{\prime}=1,3002$, dan daerah yang memiliki nilai keanekaragaman rendah yaitu Desa Guaeria dengan indeks $H^{\prime}=1,1094$ (Tabel 4)

Berdasarkan nilai indeks keanekaragaman pada ketiga stasiun yaitu pada kisaran 1,109 - 1,644 menunjukkan keanekaragaman kategori sedang karena nilai $\mathrm{H}^{\prime}$ lebih besar dari 1 dan lebih kecil dari 3 (kriteria Indeks Shanon-Wiener). Suatu komunitas dikatakan memiliki keanekaragaman yang tinggi jika komunitas itu disusun oleh banyaknya spesies. Sebaliknya suatu komunitas dikatakan memiliki keanekaragaman rendah jika komunitas itu disusun oleh sedikit spesies dan ada spesies yang dominan (Odum, 1998).

\section{KESIMPULAN}

Delapan jenis oyster yang di temukan di daerah intertidal pantai Halmahera Barat yakni Chama limbula, Saccostrea cucullata, Isognomon isognomon, Spondylus versicolor, Pinctada margaritifera, Saccostrea sp, Malleus malleus dan Hyotissa hyotis. Jenis oyster yang paling melimpah di 
daerah intertidal adalah Isognomon isognomon degan kepadatan antara $0,080-0,283$ ind $/ \mathrm{m}^{2}$ dan kurang melimpah yakni Saccostrea cucullata dengan kepadatan antara 0,007 $0,020 \mathrm{ind} / \mathrm{m}^{2}$. Keanekaragaman oyster diketiga lokasi penelitian di daerah intertidal pantai barat Halmahera termasuk dalam kategori sedang, ditandai dengan nilai indeks pada kisaran 1,109-1,644.

\section{DAFTAR PUSTAKA}

Abbot, R.T. 1991. Seashell of South East Asia. Graham Brash. Singapore.

Dahuri, R. 2003. Keanekaragaman Hayati Laut. Aset pembangunan berkelanjutan Indonesia. Penerbit PT. Gramedia. Jakarta.

Dance, P.S. 1992. SHELLS. The visual guide to more than 500 species of seashells from around the world. Photography by Matthew Ward. Published in United States by Dorling Kindersley, INC. New York.
Dharma, B.1988. Siput dan kerang Indonesia I (Indonesian Shells I). Penerbit PT Sarana Graha. Jakarta.

2005. Recent dan Fosil Indonesia Shell. PT. Ikrar Madiriabadi. Indonesia.

Fowler, J., Cohen, L. dan Jarvis, P. 1998. Practical Statistics for Field Biology. Second edition. John Wiley \& Sons Ltd, The Atrium, Sounthern Gate, Chicnhester. England.

Krebs, C.J. 1985. Ecology.Harper Collins Publishers.

Nybakken, J.W. 1992. Biologi Laut : Suatu Pendekatan Ekologis. Penerbit PT. Gramedia. Jakarta.

Odum, E.P. 1998. Dasar-dasar ekologi. Terjemahan T. Samingan dan B. Srigdanono. Gajah Mada Press. Yogyakarta.

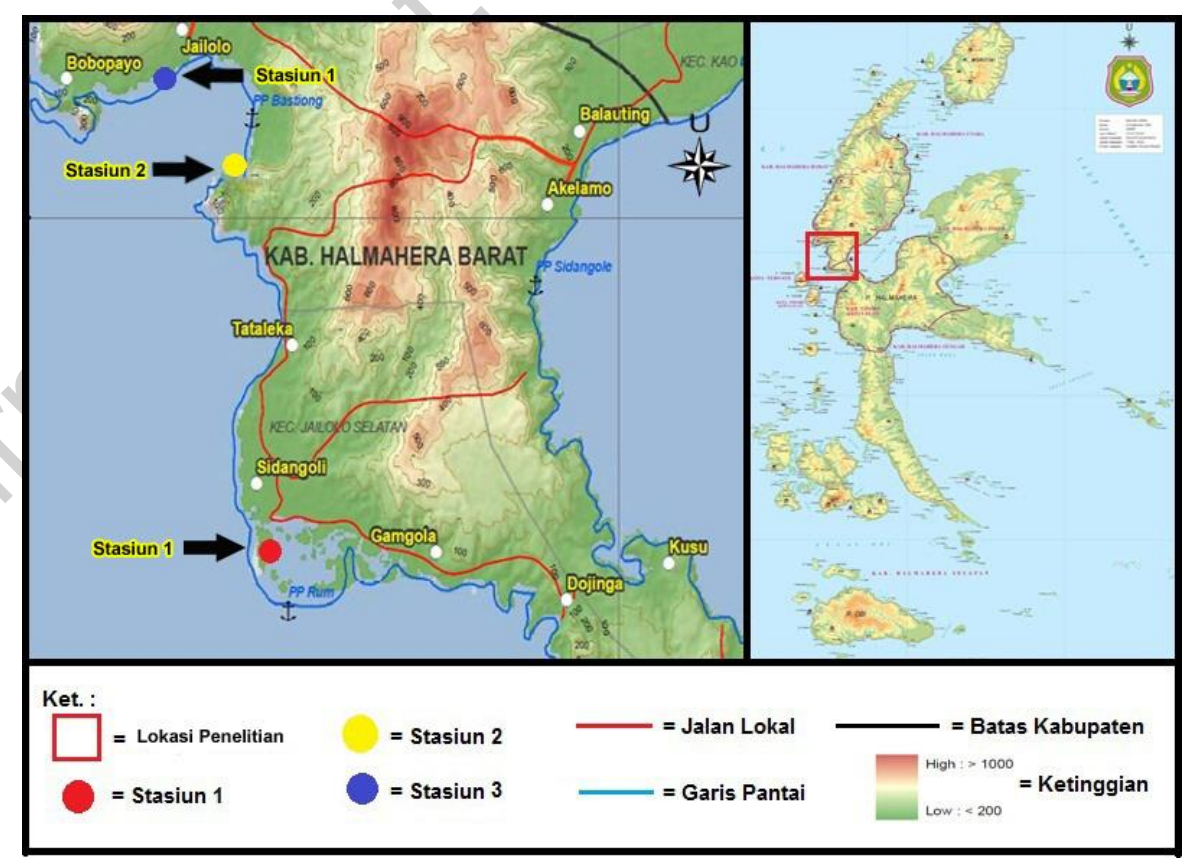

Gambar 1. Lokasi penelitian 


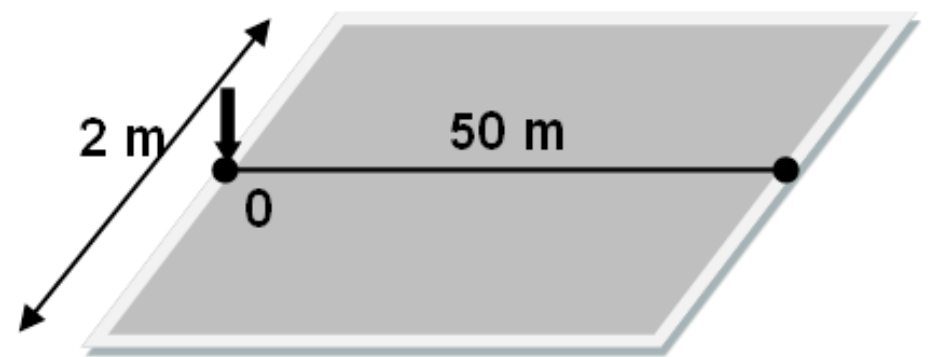

Gambar 2. Sketsa transek pita.

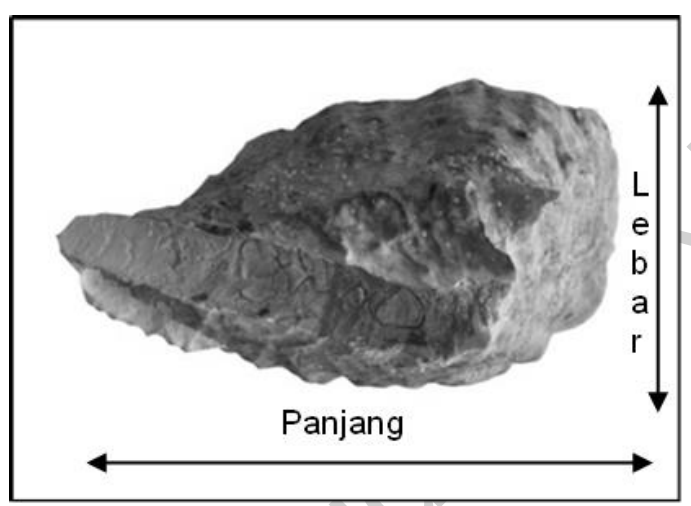

Gambar 3. Pengukuran panjang dan lebar cangkang.

Tabel 1. Spesies oyster di setiap stasiun penelitian, Maret 2012

\begin{tabular}{|c|l|c|c|c|}
\hline No. & \multicolumn{1}{|c|}{ Spesies } & $\begin{array}{c}\text { Pulau } \\
\text { Gomorotu }\end{array}$ & Desa Guaeria & $\begin{array}{c}\text { Desa } \\
\text { Guamaadu }\end{array}$ \\
\hline 1 & Chama limbula & $\checkmark$ & - & - \\
\hline 2 & Saccostrea cucullata & $\checkmark$ & $\checkmark$ & $\checkmark$ \\
\hline 3 & Saccostrea sp & $\checkmark$ & $\checkmark$ & - \\
\hline 4 & Isognomon isognomon & $\checkmark$ & $\checkmark$ & $\checkmark$ \\
\hline 5 & Malleus malleus & $\checkmark$ & - & $\checkmark$ \\
\hline 6 & Hyotissa hyotis & $\checkmark$ & - & $\checkmark$ \\
\hline 7 & Spondylus versicolor & $\checkmark$ & $\checkmark$ & $\checkmark$ \\
\hline 8 & Pinctada margaritifera & $\checkmark$ & $\checkmark$ & $\checkmark$ \\
\hline
\end{tabular}


Tabel 2. Ukuran cangkang oyster dari daerah intertidal pantai Halmahera Barat, Maret 2012

\begin{tabular}{|c|c|c|c|c|c|c|}
\hline \multirow{2}{*}{ No } & \multirow{2}{*}{ Spesies } & \multicolumn{2}{|c|}{ Panjang (cm) } & \multicolumn{2}{|c|}{ Lebar (cm) } & \multirow{2}{*}{$\begin{array}{c}\text { Ukuran Maksimum } \\
\text { panjang cangkang } \\
\text { (Carpenter dan } \\
\text { Niem, 1998) }\end{array}$} \\
\hline & & $\bar{X}$ & SD & $\overline{\boldsymbol{X}}$ & SD & \\
\hline 1 & Malleus malleus & 11,36 & 3 & 3,76 & 59 & $18 \mathrm{~cm}$ \\
\hline 2 & Sacostrea sp & 9,23 & \pm & 7,15 & & $10 \mathrm{~cm}$ \\
\hline 3 & Hyotissa hyotis & 8,32 & $\pm 3,97$ & 7,68 & $\pm 3,30$ & $18 \mathrm{~cm}$ \\
\hline 4 & Isognomon isognomon & 8,04 & $\pm 2,49$ & 3,58 & $\pm 1,04$ & $10 \mathrm{~cm}$ \\
\hline 5 & Saccostrea cucullata & 7,96 & $\pm 2,54$ & 5,33 & $\pm 1,57$ & $10 \mathrm{~cm}$ \\
\hline 6 & Pinctada margaritifera & 7,61 & $\pm 1,92$ & 7,29 & $\pm 1,69$ & $13 \mathrm{~cm}$ \\
\hline 7 & Spondylus versicolor & 6,39 & $\pm 1,88$ & 5,44 & $\pm 1,36$ & $10 \mathrm{~cm}$ \\
\hline 8 & Chama limbula & 4,48 & $\pm 0,72$ & 3,50 & $\pm 0,47$ & $6 \mathrm{~cm}$ \\
\hline
\end{tabular}

Keterangan : $\overline{\boldsymbol{X}}=$ Ukuran rata-rata, $\mathbf{S D}=$ Standar deviasi

Tabel 3. Kepadatan spesies $(K)$ dan kepadatan relatif $(K R)$ spesies oyster di daerah intertidal pantai Halmahera Barat

\begin{tabular}{|c|l|c|c|c|c|c|c|}
\hline \multirow{2}{*}{ No } & \multicolumn{2}{|c|}{ Spesies } & \multicolumn{2}{|c|}{ Pulau Gomorotu } & \multicolumn{2}{c|}{ Desa Guaeria } & \multicolumn{2}{c|}{ Desa Guamaadu } \\
\cline { 3 - 8 } & & $\begin{array}{c}\mathbf{K} \\
\left(\mathbf{i n d} / \mathbf{m}^{2}\right)\end{array}$ & $\begin{array}{c}\mathbf{K R} \\
(\%)\end{array}$ & $\begin{array}{c}\mathbf{K} \\
\left(\mathbf{i n d} / \mathbf{m}^{2}\right)\end{array}$ & $\begin{array}{c}\mathbf{K R} \\
(\%)\end{array}$ & $\begin{array}{c}\mathbf{K} \\
\left(\mathbf{i n d} / \mathbf{m}^{2}\right)\end{array}$ & $\begin{array}{c}\mathbf{K R} \\
(\%)\end{array}$ \\
\hline 1 & Isognomon isognomon & 0,283 & 41,87 & 0,083 & 62,50 & 0,080 & 57,14 \\
\hline 2 & Chama limbula & 0,167 & 24,63 & - & - & - & - \\
\hline 3 & Spondylus versicolor & 0,070 & 10,34 & 0,027 & 20,00 & 0,023 & 16,66 \\
\hline 4 & Saccostrea sp & 0,043 & 6,40 & 0,010 & 7,50 & - & - \\
\hline 5 & Hyotissa hyotis & 0,037 & 5,41 & - & - & 0,007 & 4,76 \\
\hline 6 & Malleus malleus & 0,037 & 5,41 & - & - & 0,003 & 2,38 \\
\hline 7 & Pinctada margaritifera & 0,020 & 2,95 & 0,007 & 5,00 & 0,013 & 9,52 \\
\hline 8 & Saccostrea cucullata & 0,020 & 2,95 & 0,007 & 5,00 & 0,013 & 9,52 \\
\hline & TOTAL & $\mathbf{0 , 6 7 7}$ & & $\mathbf{0 , 1 3 3}$ & & $\mathbf{0 , 1 4 0}$ & \\
\hline
\end{tabular}

Tabel 4. Nilai indeks keanekaragaman dan nilai indeks dominan spesies oyster di Halmahera Barat, Juni 2012

\begin{tabular}{|c|c|c|c|}
\hline \multirow{2}{*}{ Indeks } & \multicolumn{3}{|c|}{ Lokasi } \\
\cline { 2 - 4 } & $\begin{array}{c}\text { Pulau } \\
\text { Gomorotu }\end{array}$ & $\begin{array}{c}\text { Desa } \\
\text { Guaeria }\end{array}$ & $\begin{array}{c}\text { Desa } \\
\text { Guamaadu }\end{array}$ \\
\hline H' & 1,644 & 1,109 & 1,300 \\
\hline C & 0,258 & 0,441 & 0,375 \\
\hline
\end{tabular}

Keterangan : H' = Nilai indeks keanekaragaman, $\mathbf{C}=$ Nilai indeks dominan 